EXTENDED REPORT

\title{
A randomised controlled trial of azithromycin following surgery for trachomatous trichiasis in the Gambia
}

\author{
M J Burton, F Kinteh, O Jallow, A Sillah, M Bah, M Faye, E A N Aryee, U N Ikumapayi, \\ N D E Alexander, R A Adegbola, H Faal, D C W Mabey, A Foster, G J Johnson, R L Bailey
}

Br J Ophthalmol 2005;89:1282-1288. doi: 10.1136/bjo.2004.062489

See end of article for authors' affiliations author' affiliations

Correspondence to: Dr Matthew Burton International Centre for Eye Health, London School of Hygiene and Tropical Medicine, Keppel Street, London WClE 7HT, UK; matthew.burton@lshtm. ac.uk

Accepted for publication 29 January 2005

\begin{abstract}
Background/aim: Trachomatous trichiasis frequently returns following surgery. Several factors may promote recurrence: preoperative disease severity, surgeon ability, surgical procedure, healing responses, and infection. This study investigates whether enhanced control of infection, both of Chlamydia trachomatis and other bacteria, with azithromycin can improve surgical outcome in a trachoma control programme.

Methods: Individuals with trachomatous trichiasis were examined and operated. After surgery patients were randomised to the azithromycin or control group. The azithromycin group and children in their household were given a dose of azithromycin. Antibiotic treatment was repeated at 6 months. All patients were reassessed at 6 months and 12 months. Samples were collected for $C$ trachomatis polymerase chain reaction and general microbiology at each examination.

Results: 451 patients were enrolled. 426 (94\%) were reassessed at 1 year, of whom 176 (41.3\%) had one or more lashes touching the eye and $84(19.7 \%)$ had five or more lashes. There was no difference in trichiasis recurrence between the azithromycin and control group. Recurrent trichiasis was significantly associated with more severe preoperative trichiasis, bacterial infection, and severe conjunctival inflammation at 12 months. Significant variability in outcome was found between surgeons. Visual acuity and symptoms significantly improved following surgery.

Conclusion: In this setting, with a low prevalence of active trachoma, azithromycin did not improve the outcome of trichiasis surgery conducted by a trachoma control programme. Audit of trichiasis surgery should be routine.
\end{abstract}

$\mathrm{T}$ achoma is the leading infectious cause of blindness worldwide. Recurrent infection with Chlamydia trachomatis produces a chronic follicular conjunctivitis. Conjunctival scarring develops, leading to entropion, trichiasis, and blinding corneal opacification. Six million people are irreversibly blind from trachoma and a further 10 million have trachomatous trichiasis. ${ }^{1}$ To control trachoma the World Health Organization promotes the SAFE strategy: Surgery for trichiasis, Antibiotic distribution to reduce chlamydial infection, Facial cleanliness, and Environmental improvements to reduce transmission. ${ }^{2}$

Trichiasis surgery probably reduces the risk of visual loss, although the evidence for this is limited. ${ }^{3}$ Various procedures are used. The bilamellar tarsal rotation (BLTR) had the most favourable outcome in comparative trials and is recommended by the WHO. ${ }^{3-5}$ However, trichiasis returns in at least $20 \%$ by 2 years. ${ }^{346}$ Longer term studies find trichiasis accrues, reporting 3 year recurrence rates of more than $60 \%{ }^{7-9}$ Recurrent trichiasis is poorly understood. Several factors may influence the outcome: preoperative disease severity, surgical procedure, surgeon ability, wound healing responses, and infection. C trachomatis infection has been associated with progression of conjunctival scarring to trichiasis and recurrent trichiasis after surgery. ${ }^{10} 11$ Nonchlamydial bacterial infection is associated with progressive corneal opacification in eyes with unoperated trichiasis and recurrent trichiasis following surgery..$^{9}{ }^{12}$ Therefore, interventions that reduce conjunctival infection after surgery might improve results.

Azithromycin is effective against various bacteria including $C$ trachomatis. ${ }^{13}$ Mass azithromycin treatment controls endemic trachoma, with sustained reduction in infection a year after distribution. ${ }^{14}$ Azithromycin is active against other pathogens, including streptococci, staphylococci, and Haemophilus, which are commonly found in association with trichiasis and it can produce a short term reduction in bacterial colonisation of the conjunctiva in children. ${ }^{9}{ }^{15}$

This randomised controlled trial investigated whether trichiasis surgery results could be improved by adjunctive azithromycin treatment to an extent that would be of programmatic significance in regions with low levels of endemic active trachoma such as the Gambia. ${ }^{16}$

\section{METHODS}

\section{Ethical permission}

The study was approved by the Gambian Government/ Medical Research Council joint ethics committee. Informed consent was required for participation.

\section{Trichiasis patients}

Subject with unoperated trichiasis were identified from the Gambian National Eye Care Programme (NECP) database, community ophthalmic nurse records, and village screening. Individuals with recurrent trichiasis and pregnant women (self reported) were excluded. A series of 34 day surgery sessions were organised by the NECP at health posts between May 2001 and April 2002.

Abbreviations: BLTR, bilamellar tarsal rotation; $\mathrm{CON}$, community ophthalmic nurses; MMP, matrix metalloproteinases; NECP, National Eye Care Programme; PCR, polymerase chain reaction; PLTR, posterior lamellar tarsal rotation; RCT, randomised controlled trial; STGG, skimmed milk, tryptone, glycerol and glucose broth 


\section{Preoperative assessment}

An ophthalmologist (MJB) conducted preoperative assessments. Height, weight, and $\log$ MAR visual acuity were measured. ${ }^{17}$ Clinical signs of trachoma were graded using $2.5 \times$ loupes according to the WHO trachoma grading system. ${ }^{18}$ The number of eyelashes touching the cornea and other parts of the globe in primary position were recorded. Lagophthalmos was measured. The conjunctiva was anaesthetised with proxymetacaine $0.5 \%$ eye drops (Minims, Chauvin). A conjunctival swab sample was collected and placed in sterile skimmed milk, tryptone, glycerol, and glucose broth (STGG) for bacteriology. A second swab was collected for $C$ trachomatis polymerase chain reaction (PCR) from the upper tarsal conjunctival surface. Both were kept on ice before transfer to $-70^{\circ} \mathrm{C}$ or $-20^{\circ} \mathrm{C}$ freezers, respectively, later the same day.

\section{Surgery}

Trained community ophthalmic nurses (CON) from the NECP performed the surgery. Senior ophthalmic medical assistants supervised to ensure the standard procedure was performed correctly. The surgical technique used in the Gambia is the posterior lamellar tarsal rotation (PLTR). ${ }^{6}$ This is similar to the bilamellar tarsal rotation (BLTR), except skin and anterior lamella are not incised. Surgery was performed using aseptic techniques under local anaesthesia (lignocaine $1 \%)$. The district CON reviewed patients and removed sutures at 1 week.

\section{Randomisation}

Randomisation was to azithromycin or control group at the individual patient level. Immediately following surgery a nurse (OJ) not involved in clinical assessments or surgery administered the randomly allocated treatment. Treatment allocations were concealed in opaque sequentially numbered envelopes. Separate randomisation sequences were generated for each surgeon from random number tables and blocked in groups of four. ${ }^{19}$ Each patient was assigned the allocation in the next envelope in the sequence of their surgeon. This within surgeon blocked randomisation was done to reduce confounding from intersurgeon variability, by ensuring good balance between the two groups for each surgeon. Examiners were "blinded" to treatment allocation.

\section{Antibiotic treatment}

All patients received unsupervised tetracycline eye ointment twice a day for 2 weeks, as per Gambian guidelines. Subjects randomised to azithromycin group also received a $1 \mathrm{~g}$ dose of azithromycin. Children in the households of azithromycin group subjects were given a dose of azithromycin $(20 \mathrm{mg} / \mathrm{kg})$, following informed consent from parents. This was done to reduce the risk of re-infection with $C$ trachomatis from the immediate environment of the patient. After the 6 month assessment patients in the azithromycin group and the children were given a second dose of azithromycin by the treatment nurse.

\section{Follow up visits}

Patients were reassessed (as above) 6 months (FK) and 12 months (MJB) after surgery. At 12 months patients were asked whether they considered the vision and pain in the operated eye to be worse, the same or better, compared with how it was before surgery. Recurrent trichiasis was managed according to national guidelines: epilation for a few peripheral lashes; patients with multiple/central lashes were referred for further surgery.

\section{Laboratory tests}

Conjunctival swab samples were tested for $C$ trachomatis DNA using a PCR based assay (Amplicor CT/NG Test, Roche) with previously described modifications..$^{20}$ Bacteriology samples were plated out on blood agar (aerobic and anaerobic), McConkey's agar, gentamicin blood agar, and bacitracin chocolate agar. Plates were incubated at $37^{\circ} \mathrm{C}$ for 48 hours. Gentamicin blood agar and bacitracin chocolate agar were incubated in 5\% carbon dioxide. Isolated organisms were identified using standard bacteriological techniques. Sensitivities were assessed using antimicrobial susceptibility discs.

\section{Sample size}

This study was designed to evaluate whether azithromycin, used under the real life operational conditions of a trachoma control programme, is effective in reducing trichiasis recurrence to an extent that would be of programmatic significance in regions with low levels of endemic trachoma. Previous studies indicate trichiasis recurs in at least $20 \%$ by 1 year. ${ }^{3-8}$ We considered that for this intervention to be worth implementing the expected recurrence rate in the azithromycin group should be half that of the control group. Therefore, if the relative risk of failure in the azithromycin group were taken to be 0.5 ( $10 \%$ failure at 1 year) then a sample of 438 gives $80 \%$ power and $95 \%$ confidence to detect a difference. As well as being operationally important, this size of effect was thought feasible, given the possible impact of azithromycin on both chlamydial and bacterial infection.

\section{Data analysis}

The primary outcome was recurrent trichiasis: one or more lashes touching any part of the globe in primary position following surgery. Secondary outcomes included visual acuity, conjunctival infection, and corneal opacification. ${ }^{18}$ For visual acuities of counting fingers or less, logMAR values were attributed: counting fingers 2.0, hand movements 2.5, and perception of light 3.0.

Data were analysed in Stata 7. In bilateral cases only the eye with more severe trichiasis was included in the study analysis. The Wilcoxon signed rank test was used to examine change in degree of trichiasis before and after surgery. Paired $t$ tests were used to examine change in visual acuity. Multivariable logistic regression models were developed to investigate risk factors for recurrent trichiasis. All models included sex, age, and treatment allocation. Additional terms were added in a stepwise manner.

\section{RESULTS}

A total of 451 people with trachomatous trichiasis were enrolled; predominantly women $(70.5 \%)$ with a mean age of 57 years (table 1). Visually disabling corneal opacification was present in $30 \%$ of eyes (moderate/severe scarring over the pupil, CC2/CC3). ${ }^{18}$ Severity of trichiasis varied considerably (median: eight lashes, interquartile range: 5-16; total range: 0 (epilating)-74). C trachomatis DNA was detected in $5 \%$ of individuals. Bacterial pathogens were cultured from $29.8 \%$ of eyes.

Following surgery 216 individuals were randomised to receive azithromycin and 235 to the control group (fig 1). Baseline characteristics of the two groups were comparable (table 1). Follow up rates were $91 \%$ and $94 \%$ at 6 months and 12 months, respectively; $98 \%$ of those alive at 12 months. Reasons for no follow up are given in figure 1 .

The prevalence of any trichiasis was $31.5 \%$ and $41.3 \%$ at 6 months and 12 months, respectively (table 2 ). The recurrence rate was $37.9 \%$ at 12 months in fellow eyes that were operated on but not included in the study analysis. For all subjects, the median number of lashes touching the globe at 
Table 1 Patient characteristics and preoperative clinical parameters, subdivided by treatment allocation

\begin{tabular}{|c|c|c|c|c|c|c|}
\hline \multirow[b]{2}{*}{ Demographics: } & \multicolumn{2}{|l|}{$\begin{array}{l}\text { All } \\
(n=451)\end{array}$} & \multicolumn{2}{|c|}{$\begin{array}{l}\text { Azithromycin } \\
(n=216)\end{array}$} & \multicolumn{2}{|l|}{$\begin{array}{l}\text { Control } \\
(n=235)\end{array}$} \\
\hline & & & & & & \\
\hline Sex, female & 318 & $(70.5 \%)$ & 152 & $(70.4 \%)$ & 166 & (70.6\%) \\
\hline Age, mean (IQR) & 57.3 & $(48-70)$ & 57.3 & $(47-70)$ & 57.2 & $(48-70)$ \\
\hline BMI (IQR) & 20.4 & $(18.4-21.9)$ & 20.3 & (18.3-21.9) & 20.6 & $(18.5-21.9)$ \\
\hline \multicolumn{7}{|l|}{ Ethnicity: } \\
\hline Mandinka & 178 & $(39.4 \%)$ & 88 & $(40.7 \%)$ & 90 & $(38.3 \%)$ \\
\hline Wolof & 154 & $(34.2 \%)$ & 73 & $(33.8 \%)$ & 81 & $(34.5 \%)$ \\
\hline Jola & 58 & $(12.8 \%)$ & 26 & (12.0\%) & 32 & $(13.6 \%)$ \\
\hline Fula & 33 & $(7.3 \%)$ & 15 & $(6.9 \%)$ & 18 & $(7.7 \%)$ \\
\hline Manjago & 12 & $(2.7 \%)$ & 6 & $(2.9 \%)$ & 6 & $(2.5 \%)$ \\
\hline Sarahule & 7 & $(1.6 \%)$ & 4 & $(1.8 \%)$ & 3 & $(1.3 \%)$ \\
\hline Other & 9 & $(2.0 \%)$ & 4 & $(1.9 \%)$ & 5 & $(2.1 \%)$ \\
\hline \multicolumn{7}{|l|}{ Corneal opacity: } \\
\hline CC 0 & 235 & $(52.1 \%)$ & 119 & $(55.1 \%)$ & 116 & $(49.4 \%)$ \\
\hline CC 1 & 83 & $(18.4 \%)$ & 34 & $(15.7 \%)$ & 49 & $(20.1 \%)$ \\
\hline CC 2 & 62 & $(13.8 \%)$ & 31 & $(14.4 \%)$ & 31 & $(13.2 \%)$ \\
\hline CC 3 & 71 & $(15.7 \%)$ & 32 & $(14.8 \%)$ & 39 & $(16.8 \%)$ \\
\hline \multicolumn{7}{|l|}{ Trichiasis (number of lashes): } \\
\hline 0 (epilate) & 63 & $(14.0 \%)$ & 24 & $(11.1 \%)$ & 39 & $(16.6 \%)$ \\
\hline $1-4$ & 45 & $(10.0 \%)$ & 26 & $(12.0 \%)$ & 19 & $(8.1 \%)$ \\
\hline $5-9$ & 149 & $(33.0 \%)$ & 70 & $(32.4 \%)$ & 79 & (33.6\%) \\
\hline $10-19$ & 101 & $(22.4 \%)$ & 50 & $(23.2 \%)$ & 51 & $(21.7 \%)$ \\
\hline $20+$ & 93 & $(20.6 \%)$ & 46 & $(21.3 \%)$ & 47 & $(20.0 \%)$ \\
\hline Mean no of lashes (95\% Cl) & 12.4 & (11.2 to 13.5$)$ & 12.8 & (11.1 to 14.5$)$ & 12.0 & (10.4 to 13.7$)$ \\
\hline \multicolumn{7}{|l|}{ Conjunctival inflammation: } \\
\hline PO & 64 & $(14.2 \%)$ & 33 & $(15.3 \%)$ & 31 & $(13.2 \%)$ \\
\hline P1 & 118 & $(26.2 \%)$ & 55 & $(25.5 \%)$ & 63 & $(26.8 \%)$ \\
\hline P2 & 149 & $(33.0 \%)$ & 64 & $(29.6 \%)$ & 85 & $(36.2 \%)$ \\
\hline P3 & 120 & $(26.6 \%)$ & 64 & $(29.6 \%)$ & 56 & $(23.8 \%)$ \\
\hline \multicolumn{7}{|l|}{ Infection: } \\
\hline C trachomatis (PCR+) & $22 / 443$ & $(5.0 \%)$ & $10 / 212$ & $(4.7 \%)$ & $12 / 231$ & $(5.2 \%)$ \\
\hline Other bacteria & $132 / 443$ & $(29.8 \%)$ & $60 / 210$ & $(28.6 \%)$ & $72 / 233$ & $(30.9 \%)$ \\
\hline
\end{tabular}

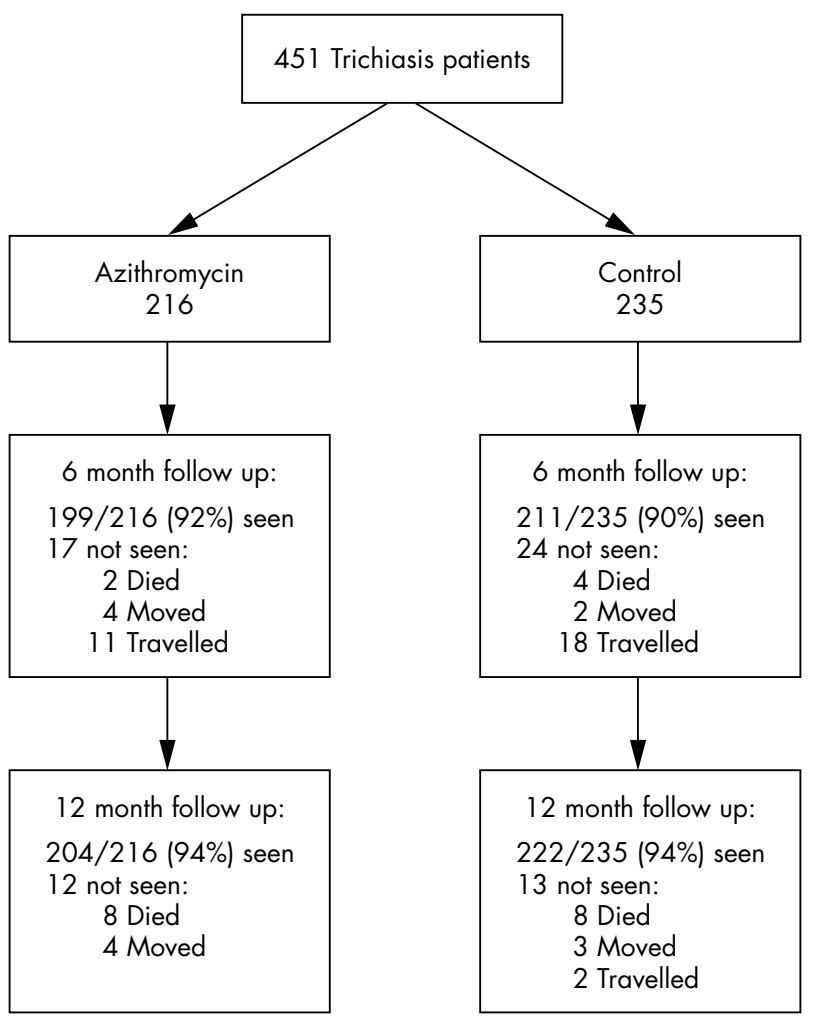

Figure 1 Flow diagram summarising the treatment and follow up coverage at 6 months and 12 months after surgery.
12 months was 0 (interquartile range: $0-3$; total range: $0-$ 53). Trichiasis severity was significantly reduced (Wilcoxon signed rank test: $\mathrm{z}=15.2, \mathrm{p}<0.001)$. For subjects with recurrent trichiasis the median was 10 lashes before surgery (interquartile range: 4-22; total range: 0 (epilating) - 74) and four lashes at 12 months (interquartile range: 1-8; total range: 0 (epilating) - 53). This subgroup had a significant reduction in trichiasis severity (Wilcoxon signed rank test: $\mathrm{z}=7.1, \mathrm{p}<0.001)$. Postoperatively, one patient developed $\mathrm{a}$ lid infection, which settled with oral antibiotics and two individuals had defective lid closure $(<2 \mathrm{~mm}$ lagophthalmos).

Univariate associations between various factors and recurrent trichiasis at 12 months are presented in table 3.

Multivariable logistic regression models were developed for any trichiasis and 5+ lashes at 12 months (table 4). Azithromycin treatment did not affect the outcome. Recurrent trichiasis was associated with more severe preoperative trichiasis, severe conjunctival inflammation, and bacterial infection at 12 months. $C$ trachomatis infection was not associated with recurrent trichiasis in these models and therefore dropped.

Seventeen nurses performed surgery (mean: 26 cases, SD 22.9, range: 2-92). Trichiasis recurrence rates varied significantly between surgeons (median: 40\%; interquartile range: $22-49 \%$; total range: $0-83 \%$; Pearson $\chi^{2}: \chi^{2}=63.1$, $\mathrm{df}=16, \mathrm{p}<0.001)$. Likelihood ratio testing between multivariable logistic regression models for recurrent trichiasis with and without surgeons was done. This indicated intersurgeon variability remained significant after adjusting for other factors, including preoperative disease severity $\left(\chi^{2}=55.9, \mathrm{p}<0.001\right)$. The odds ratio for azithromycin treatment changed negligibly when models were adjusted for surgeon ( $\mathrm{OR}=0.99,95 \%$ CI 0.63 to $1.59, \mathrm{p}=0.989)$; this is as expected, given the randomisation within surgeon. 
Table 2 Severity of recurrent trichiasis at 6 months and 12 months after surgery, subdivided by treatment allocation

\begin{tabular}{|c|c|c|c|c|c|c|}
\hline \multirow{4}{*}{$\begin{array}{l}6 \text { Months } \\
\text { Any trichiasis } \\
\text { Any touching the cornea } \\
\text { No of lashes touching eye: }\end{array}$} & \multirow{2}{*}{$\begin{array}{l}\text { All } \\
n=410\end{array}$} & \multirow[b]{3}{*}{$(31.5 \%)$} & \multicolumn{2}{|c|}{ Azithromycin } & \multicolumn{2}{|l|}{ Control } \\
\hline & & & $n=199$ & & $n=211$ & \\
\hline & 129 & & 74 & $(37.2 \%)$ & 55 & $(26.1 \%)$ \\
\hline & 99 & $(24.1 \%)$ & 54 & $(27.1 \%)$ & 45 & $(21.3 \%)$ \\
\hline 0 & 281 & $(68.5 \%)$ & 125 & $(62.8 \%)$ & 156 & (73.9\%) \\
\hline $1-4$ & 70 & $(17.1 \%)$ & 42 & $(21.1 \%)$ & 28 & (13.3\%) \\
\hline $5-9$ & 25 & $(6.1 \%)$ & 13 & $(6.5 \%)$ & 12 & $(5.7 \%)$ \\
\hline $10-19$ & 15 & (3.7\%) & 6 & (3.0\%) & 9 & $(4.3 \%)$ \\
\hline $20+$ & 19 & $(4.6 \%)$ & 13 & $(6.5 \%)$ & 6 & $(2.8 \%)$ \\
\hline Mean no of lashes $(95 \% \mathrm{Cl})$ & 4.1 & (3.4 to 5.0$)$ & 3.9 & (3.0 to 5.1$)$ & 4.4 & (3.3 to 5.9$)$ \\
\hline 12 Months & $n=426$ & & $n=204$ & & $n=222$ & \\
\hline Any trichiasis & 176 & $(41.3 \%)$ & 84 & $(41.2 \%)$ & 92 & $(41.4 \%)$ \\
\hline Any touching the cornea & 139 & $(32.6 \%)$ & 64 & (31.4\%) & 75 & (33.8\%) \\
\hline \multicolumn{7}{|l|}{ No of lashes touching eye: } \\
\hline 0 (No epilation) & 250 & $(58.7 \%)$ & 120 & $(58.8 \%)$ & 130 & $(58.6 \%)$ \\
\hline 0 (Epilate) & 13 & $(3.1 \%)$ & 7 & $(3.4 \%)$ & 6 & $(2.7 \%)$ \\
\hline $1-4$ & 79 & (18.4\%) & 34 & (16.7\%) & 45 & $(20.3 \%)$ \\
\hline $5-9$ & 45 & $(10.6 \%)$ & 26 & (12.7\%) & 19 & $(8.5 \%)$ \\
\hline $10-19$ & 20 & $(4.7 \%)$ & 6 & $(3.0 \%)$ & 14 & (6.3\%) \\
\hline $20+$ & 19 & $(4.5 \%)$ & 11 & $(5.4 \%)$ & 8 & (3.6\%) \\
\hline Mean no of lashes $(95 \% \mathrm{CI})$ & 4.5 & (3.7 to 5.3 ) & 4.7 & $(3.6$ to 6.0$)$ & 4.3 & (3.4 to 5.4$)$ \\
\hline
\end{tabular}

Table 3 Univariate associations between various factors and recurrent trichiasis (any trichiasis and 5+ lashes) at 12 months after surgery

\begin{tabular}{|c|c|c|c|c|c|c|}
\hline & \multicolumn{3}{|c|}{ Any trichiasis } & \multicolumn{3}{|c|}{ 5+ Lashes } \\
\hline & OR & $95 \% \mathrm{Cl}$ & p Value & OR & $95 \% \mathrm{Cl}$ & p Value \\
\hline Sex (female) & 0.65 & 0.43 to 0.99 & 0.050 & 0.75 & 0.45 to 1.25 & 0.264 \\
\hline Age $60+$ years & 1.63 & 1.10 to 2.41 & 0.015 & 1.73 & 1.05 to 2.84 & 0.031 \\
\hline Azithromycin treatment & 0.99 & 0.67 to 1.46 & 0.956 & 1.18 & 0.73 to 1.90 & 0.499 \\
\hline $1-4$ & 1 & - & - & 1 & - & - \\
\hline $5-9$ & 1.06 & 0.49 to 2.26 & 0.889 & 1.10 & 0.29 to 4.20 & 0.886 \\
\hline $10-19$ & 2.19 & 1.01 to 4.74 & 0.047 & 4.60 & 1.31 to 16.2 & 0.017 \\
\hline $20+$ & 3.93 & 1.78 to 8.65 & 0.001 & 10.28 & 2.95 to 35.8 & $<0.001$ \\
\hline \multicolumn{6}{|l|}{ Severe inflammation (P3/TI) } & $<0.001$ \\
\hline Baseline & 1.92 & 1.24 to 2.97 & 0.003 & 2.42 & 1.46 to 3.99 & 0.001 \\
\hline 12 Months & 7.38 & 3.78 to 14.4 & $<0.001$ & 6.53 & 3.62 to 11.8 & $<0.001$ \\
\hline \multicolumn{7}{|l|}{ Bacterial Infection: } \\
\hline Baseline & 1.61 & 1.05 to 2.46 & 0.028 & 2.05 & 1.24 to 3.37 & 0.005 \\
\hline 12 Months & 1.66 & 0.95 to 2.88 & 0.070 & 4.30 & 2.40 to 7.70 & $<0.001$ \\
\hline \multicolumn{7}{|l|}{ C trachomatis infection: } \\
\hline Baseline & 2.73 & 1.07 to 7.00 & 0.036 & 1.37 & 0.48 to 3.88 & 0.556 \\
\hline 12 Months & $\infty$ & - & $<0.001$ & 4.12 & 0.57 to 29.8 & 0.159 \\
\hline
\end{tabular}

Table 4 Multivariable logistic regression models for any trichiasis and 5+ lashes at 12 months after surgery

\begin{tabular}{|c|c|c|c|c|c|c|}
\hline \multirow[b]{2}{*}{ Variable } & \multicolumn{3}{|c|}{ Any trichiasis } & \multicolumn{3}{|c|}{ 5+ Lashes } \\
\hline & OR & $95 \% \mathrm{Cl}$ & p Value & $\overline{\mathrm{OR}}$ & $95 \% \mathrm{Cl}$ & p Value \\
\hline Sex (female) & 0.78 & 0.48 to 1.26 & 0.304 & 0.87 & 0.47 to 1.59 & 0.644 \\
\hline \multicolumn{7}{|l|}{ Age (years): } \\
\hline$<50$ & 1.00 & - & - & 1.00 & - & - \\
\hline $50-59$ & 0.94 & 0.48 to 1.83 & 0.872 & 0.73 & 0.30 to 1.78 & 0.483 \\
\hline $60-69$ & 1.72 & 0.96 to 3.09 & 0.070 & 0.92 & 0.42 to 1.98 & 0.823 \\
\hline$>70$ & 1.39 & 0.75 to 2.55 & 0.294 & 1.44 & 0.67 to 3.07 & 0.347 \\
\hline Azithromycin treatment & 0.98 & 0.63 to 1.51 & 0.919 & 1.27 & 0.73 to 2.21 & 0.407 \\
\hline $10+$ lashes at baseline & 1.74 & 1.12 to 2.71 & 0.014 & 3.69 & 2.06 to 6.60 & $<0.001$ \\
\hline Bacterial infection at baseline & 1.33 & 0.81 to 2.17 & 0.261 & 1.11 & 1.22 to 4.94 & 0.722 \\
\hline Bacterial infection at 12 months & 0.84 & 0.44 to 1.61 & 0.604 & 2.45 & 1.22 to 4.94 & 0.012 \\
\hline Severe inflammation at 12 months & 6.41 & 3.17 to 12.9 & $<0.001$ & 5.90 & 3.02 to 11.5 & $<0.001$ \\
\hline
\end{tabular}


Table 5 Conjunctival bacterial infection and relationship with trichiasis severity before surgery and at 12 months

\begin{tabular}{|c|c|c|c|c|c|c|}
\hline \multirow{3}{*}{$\begin{array}{l}\text { Pathogen cultured } \\
\text { No of lashes touching eye: }\end{array}$} & \multicolumn{3}{|l|}{ Baseline } & \multicolumn{3}{|l|}{12 Months } \\
\hline & $132 / 443$ & $(29.8 \%)$ & & $61 / 410$ & (14.9\%) & \\
\hline & & & & & & \\
\hline 0 (No epilation) & - & - & & $30 / 242$ & (12.4\%) & \\
\hline 0 (Epilate) & $11 / 62$ & (17.7\%) & & $2 / 22$ & $(9.1 \%)$ & \\
\hline $1-4$ & $10 / 45$ & $(22.2 \%)$ & & $2 / 70$ & $(2.9 \%)$ & \\
\hline $5-9$ & $31 / 145$ & $(21.4 \%)$ & & $10 / 39$ & $(25.6 \%)$ & \\
\hline $10-19$ & $25 / 101$ & $(24.8 \%)$ & & $8 / 18$ & (44.4\%) & \\
\hline $20+$ & $55 / 90$ & (61.1\%) & & $9 / 19$ & $(47.4 \%)$ & \\
\hline Association between infection and & OR & $95 \% \mathrm{Cl}$ & $p$ Value & OR & $95 \% \mathrm{Cl}$ & p Value \\
\hline $5+$ lashes & 2.02 & 1.19 to 3.43 & 0.009 & 4.15 & 2.33 to 7.42 & $<0.001$ \\
\hline 10+ lashes & 2.77 & 1.82 to 4.22 & $<0.001$ & 6.03 & 2.96 to 12.3 & $<0.001$ \\
\hline
\end{tabular}

Table 6 Pathological conjunctival bacterial isolates before and after surgery

\begin{tabular}{|c|c|c|c|c|c|c|}
\hline & \multicolumn{2}{|c|}{ Baseline } & \multicolumn{2}{|c|}{6 Months } & \multicolumn{2}{|c|}{12 Months } \\
\hline & No & $\%$ & No & $\%$ & No & $\%$ \\
\hline Streptococcus pneumoniae & 61 & $(42.4)$ & 19 & (20.7) & 20 & (26.0) \\
\hline$S$ viridans & 12 & (8.3) & 15 & (8.7) & 1 & (1.3) \\
\hline Streptococcus group A & 2 & $(1.4)$ & 2 & $(2.2)$ & 1 & $(1.3)$ \\
\hline Streptococcus group C & 12 & (8.3) & 1 & (1.1) & 8 & $(10.4)$ \\
\hline Streptococcus group D & 1 & (0.7) & 1 & (1.1) & - & \\
\hline Streptococcus group G & 3 & (2.1) & 1 & (1.1) & - & \\
\hline Streptococcus spp & 12 & (8.3) & 5 & (5.4) & 6 & $(7.8)$ \\
\hline Staphylococcus aureus & 16 & (11.1) & 26 & (28.3) & 16 & $(20.8)$ \\
\hline Pseudomonas aeruginosa & 3 & (2.1) & 1 & (1.1) & 1 & (1.3) \\
\hline Moraxella & 3 & (2.1) & 5 & (5.4) & 5 & (12.0) \\
\hline Haemophilus influenzae & 1 & $(0.7)$ & 2 & $(2.2)$ & 10 & (12.0) \\
\hline Klebsiella & 6 & $(4.2)$ & 15 & (16.3) & 2 & $(2.6)$ \\
\hline Neisseria spp & 3 & (2.1) & 1 & (1.1) & 1 & $(1.3)$ \\
\hline Coliform spp & 5 & (3.5) & 3 & (3.3) & 3 & (3.9) \\
\hline Proteus & 1 & $(0.7)$ & - & & - & \\
\hline Escherichia coli & 1 & $(0.7)$ & - & & - & \\
\hline Salmonella & - & & 2 & $(2.2)$ & - & \\
\hline Serratia & 1 & $(0.7)$ & - & & 1 & (1.3) \\
\hline Enterobacter sakazakii & 1 & $(0.7)$ & - & & - & \\
\hline Fungus & - & & - & & 2 & (2.6) \\
\hline Total & 144 & & 92 & & 77 & \\
\hline
\end{tabular}

C trachomatis was detected in 22,16 , and four samples at baseline, 6 months, and 12 months, respectively. At 6 months there was a significant reduction in chlamydial infection in azithromycin compared to control group (OR 0.14. $\mathrm{p}=0.010 .95 \%$ CI 0.03 to 0.63$)$. At 12 months there was one chlamydial infection in the azithromycin group and three in the control group.

Bacterial pathogens were isolated from $29.8 \%$ before surgery and $14.9 \%$ at 12 months (table 5 ). Twelve $(9.1 \%$ ) had mixed infections at baseline. Infection was more common as trichiasis severity increased. The principal risk factor for bacterial infection was trichiasis. Azithromycin treatment was not associated with less infection at 6 months or 12 months. Various organisms were cultured (table 6). Seasonal variation in organisms was observed, with more Klebsiella during the wet season (6 months).

Corneal opacification at baseline was associated with increasing age, severe trichiasis, severe inflammation, and bacterial infection (table 7). Corneal opacification progressed in $68(16 \%)$, was unchanged in $303(71 \%)$, and decreased in $54(13 \%)$ at 12 months. Progression of corneal opacification was associated with the presence of five or more lashes at 12 months, when compared to individuals without corneal opacification (OR 2.76, 95\% CI: 1.42 to $5.35, \mathrm{p}=0.003$ ). By 1 year 27 individuals had developed new corneal opacification (CC2 or CC3), of whom $14(52 \%)$ had no recurrent trichiasis. Interobserver agreement for the diagnosis of corneal opacification (CC2/CC3) was good (kappa $=0.76)$.

Severe conjunctival inflammation (P3/TI) at 1 year was independently associated with the presence of bacterial infection and severe trichiasis at 12 months (table 8 ).

Visual acuity improved in $57.6 \%$ and deteriorated in $28.4 \%$ of eyes by 12 months. The 297 eyes with vision good enough to be tested by $\log$ MAR had a mean improvement of 0.144 logMAR units (paired two sided $t$ test: $\mathrm{p}<0.0001,95 \%$ CI 0.108 to 0.180 ). When the additional 118 eyes with acuity between counting fingers and perception of light were included the mean improvement was $0.121 \log$ MAR units (paired two sided $t$ test: $\mathrm{p}<0.0001,95 \%$ CI 0.07 to 0.17 ). There was no significant difference in improvement between those with or without recurrent trichiasis (unpaired two sided $t$ test: mean difference $0.013, \mathrm{p}=0.725,95 \% \mathrm{CI}:-0.060$ to 0.087 ). Before surgery $79 \%$ reported eye pain; $18 \%$ had constant pain. Epilation was common $(38 \%>1$ per week). Subjectively, 1 year after surgery $77 \%$ thought they could see better with the operated eye; $94.3 \%$ considered the operated eye to be more comfortable, while $5.7 \%$ felt it was the same or worse.

\section{DISCUSSION}

Blinding trachoma is a progressive inflammatory cicatricial process, which is probably driven by recurrent infection with 
Table 7 Multivariable logistic regression model for visually disabling corneal opacification (CC2 or CC3) before surgery

\begin{tabular}{llll}
\hline Variable & OR & $95 \% \mathrm{Cl}$ & p Value \\
\hline Age 60+ years & 3.07 & 1.90 to 4.96 & $<0.001$ \\
Severe trichiasis (10+ lashes) & 2.33 & 1.46 to 3.71 & $<0.001$ \\
Severe conjunctival inflammation (P3) & 2.89 & 1.46 to 3.90 & 0.001 \\
Bacterial infection & 2.12 & 1.32 to 3.45 & 0.002 \\
\hline
\end{tabular}

Table 8 Multivariable logistic regression model for severe conjunctival inflammation before surgery and at 12 months

\begin{tabular}{|c|c|c|c|c|c|c|}
\hline \multirow[b]{2}{*}{ Variable } & \multicolumn{3}{|c|}{ Baseline } & \multicolumn{3}{|c|}{12 Months } \\
\hline & OR & $95 \% \mathrm{Cl}$ & $\mathrm{p}$ Value & OR & $95 \% \mathrm{Cl}$ & p Value \\
\hline Severe trichiasis (10+ lashes) & 2.58 & 1.64 to 4.07 & $<0.001$ & 8.71 & 4.02 to 18.9 & $<0.001$ \\
\hline Bacterial infection & 2.02 & 1.27 to 3.22 & 0.003 & 2.47 & 1.12 to 5.11 & 0.015 \\
\hline C trachomatis infection & 1.86 & 0.73 to 4.71 & 0.190 & 1.68 & 0.13 to 21.8 & 0.691 \\
\hline
\end{tabular}

$C$ trachomatis and bacterial pathogens. Trichiasis surgery reduces the risk of blindness; however, trichiasis frequently returns limiting the benefit. ${ }^{34-8}$ Recurrent trichiasis could be due in part to progressive cicatricial disease driven by infection. ${ }^{78}$ We investigated the impact of adjunctive azithromycin on trichiasis surgery, within a trachoma control programme. Preoperatively the azithromycin and control groups were comparable. There was no difference in recurrence rates between the two groups. Therefore, in this setting, which currently has a low prevalence of active trachoma (6\% in children $0-15$ years), azithromycin did not improve the 1 year surgical results of a control programme. ${ }^{16}$

C trachomatis was uncommon (5\%) and not associated with recurrent trichiasis. Azithromycin was associated with significantly less chlamydial infection at 6 months, compared with tetracycline alone. The overall downward trend in the prevalence of $C$ trachomatis infection in the control group was probably the result of a combination of tetracycline treatment and the downward secular trend previously observed in this region. ${ }^{16}$ In this low prevalence setting $C$ trachomatis probably contributes little to recurrent trichiasis. This study was powered to detect a difference of practical programmatic significance (halving of recurrence rate), and does not exclude a more subtle effect of azithromycin. In higher prevalence regions the organism may contribute more to recurrence and azithromycin could improve outcomes.

Bacterial infection was common preoperatively (29.8\%). Trichiasis was the principal risk factor for infection and isolation rates increased with severity. Trichiasis probably facilitates recurrent bacterial inoculation of the conjunctiva and impedes resolution of infection. Surgery probably reduces susceptibility to bacteria, explaining the halving of infection at 12 months (14.9\%). Azithromycin was not associated with less bacterial infection 6 months after treatment; recurrent trichiasis (equally common in both groups) predisposes the conjunctiva to bacteria long after the antibiotic is active. ${ }^{13}$ We have reported a similar association between bacterial infection and recurrent trichiasis 4 years after surgery. ${ }^{9}$ Currently, it is unknown whether bacterial infection is a cause or effect of recurrent trichiasis but this merits further investigation.

The recurrence rate $(41 \%)$ was higher than some previously reported series ${ }^{36}$ but comparable with others. ${ }^{7-9}$ Comparisons of alternative techniques found the BLTR to have the most favourable outcome. ${ }^{34}$ The Gambia, in common with several trachoma endemic countries, uses the PLTR, which was not formally compared with the BLTR. ${ }^{6}$ It is possible that under operational conditions they may have different intersurgeon reliability.

There was significant intersurgeon variation in trichiasis recurrence after adjusting for preoperative disease severity. Surgery followed national guidelines and was supervised by senior staff. However, subtle variations in technique-for example, in suture tension and dissection between anterior and posterior lamellae, may influence outcome. This finding emphasises the importance of ongoing surgical audit, so appropriate training and support can be provided where results are less good. There is little published on intersurgeon variability. One study reported variable recurrence rates between three surgeons $(28-73 \%)$, which were attributed to variations in preoperative disease severity. ${ }^{4}$ Recurrence from poor technique probably develops in the early postoperative period. This was not assessed as the focus of this study was the long term impact of azithromycin. Within surgeon randomisation of patients minimises potential confounding from intersurgeon variability.

Severe preoperative trichiasis was an independent risk factor for recurrence. More severe trichiasis probably reflects more severe scarring, which makes surgery difficult and may be associated with progressive postoperative cicatricial disease. Others have reported similar associations. ${ }^{421}{ }^{22}$ In many countries, including the Gambia, epilation is practised initially and surgery is deferred until "major trichiasis" (5+ lashes) develops. This study suggests that it may be better to operate earlier in the natural history of the disease before severe trichiasis develops. It may also be appropriate to develop graded referral systems in which severe trichiasis cases are operated on by senior surgeons.

Severe inflammation was independently associated with severe trichiasis and bacterial infection but not $C$ trachomatis. Earlier studies found an association between conjunctival inflammation and trichiasis. ${ }^{912}$ Several factors may promote inflammation: infection, mechanical irritation from lashes, dry eye, or an immunological process. In many situations chronic, severe inflammation produces scarring. Severe inflammatory trachoma (TI) in children is associated with increased expression of matrix metalloproteinases (MMP) and risk of subsequent scarring. ${ }^{23-25}$ Therefore, severe inflammation following surgery may produce additional scarring and recurrent trichiasis. Pharmacological inhibition 
of MMPs may offer a way to control the inflammatory cicatricial process before or after surgery.

Surgery produced significant improvements in subjective symptoms, visual acuity, burden of trichiasis and bacterial infection. Improvement in visual acuity was similar to an earlier study. ${ }^{3}$ It was probably due to reduced ocular discharge and some restoration of the corneal surface. Corneal opacification progressed in $16 \%$ of individuals and was significantly associated with recurrent trichiasis. The development of new corneal opacification in the absence of recurrent trichiasis is an interesting observation, which suggests that other factors contribute to blinding trachoma. Mechanisms such as dry eye and conjunctival inflammation should be investigated, as correcting trichiasis alone may be insufficient to prevent blindness in some patients.

In conclusion, this study does not support the use of adjunctive azithromycin in trichiasis surgery in regions with a low prevalence of active trachoma such as the Gambia. Some useful insights into recurrent trichiasis have been gained. Recurrent trichiasis is a significant problem, which was associated with severe preoperative trichiasis, intersurgeon variability, conjunctival inflammation, and conjunctival bacterial infection. There is a need for further research into the causes of recurrent trichiasis and to evaluate interventions to improve the outcome of surgery.

\section{ACKNOWLEDGEMENTS}

The authors would like to thank the community ophthalmic nurses of the Gambian National Eye Care Programme who participated in this study for all their hard work in identifying trichiasis patients and performing the surgery. We would also like to thank the Programme National de Lutte Contre La Cecite de la Republique du Senegal and their ophthalmic nurses who participated in are of the surgery camps under the auspices of the Health for Peace Initiative between the Gambian and Senegalese governments. The authors thank Dr Katie Burton, Dr Heather Nunnerly, and Mrs Wendy Burton for preparing the randomised treatment allocation sequences.

\section{Authors' affiliations \\ M J Burton, N D E Alexander, D C W Mabey, A Foster, G J Johnson, R L Bailey, London School of Hygiene and Tropical Medicine, London, UK \\ M J Burton, O Jallow, E A N Aryee, U N Ikumapayi, R A Adegbola, R L Bailey, Medical Research Council Laboratories, Fajara, Gambia F Kinteh, O Jallow, A Sillah, M Bah, H Faal, National Eye Care Programme, Gambia \\ M Faye, Programme National de Lutte Contre La Cecite de la Republique du Senegal \\ G J Johnson, Division of Epidemiology and International Eye Health, Institute of Ophthalmology, London, UK \\ Funding: The funders of this study had no part in study design; in the collection, analysis, and interpretation of data; in the writing of the report; and in the decision to submit the paper for publication. This study was principally funded by a grant from the International Trachoma}

Initiative (01-030) with additional support from the Wellcome Trust and Sight Savers International. The manufacturer, Pfizer Inc, donated the azithromycin used in the trial.

\section{REFERENCES}

1 Thylefors B, Negrel AD, Pararajasegaram R, et al. Global data on blindness. Bull World Health Organ 1995;73:1 15-21.

2 World Health Organization. Global elimination of blinding trachoma. Resolution WHA 51.11 adopted by the World Health Assembly 16 May 1998.

3 Reacher MH, Munoz B, Alghassany A, et al. A controlled trial of surgery for trachomatous trichiasis of the upper lid. Arch Ophthalmol 1992;1 10:667-74.

4 Reacher MH, Huber MJ, Canagaratnam R, et al. A trial of surgery for trichiasis of the upper lid from trachoma. Br J Ophthalmol 1990;74:109-13.

5 Reacher MH, Foster A, Huber MJ. Trichiasis surgery for trachoma. The bilamellar tarsal rotation procedure. Geneva: World Health Organization, 1993.

6 Bog H, Yorston D, Foster A. Results of community-based eyelid surgery for trichiasis due to trachoma. Br J Ophthalmol 1993;77:81-3.

7 Bowman RJ, Jatta B, Faal H, et al. Long-term follow-up of lid surgery for trichiasis in the Gambia: surgical success and patient perceptions. Eye 2000;14:864-8.

8 Khandekar R, Mohammed AJ, Courtright P. Recurrence of trichiasis: a longterm follow-up study in the Sultanate of Oman. Ophthalmic Epidemiol $2001 ; 8: 155-61$.

9 Burton MJ, Bowman RJ, Faal $\mathrm{H}$, et al. Long term outcome of trichiasis surgery in the Gambia. Br J Ophthalmol 2005:89:575-80.

10 Munoz B, Bobo L, Mkocha H, et al. Incidence of trichiasis in a cohort of women with and without scarring. Int J Epidemiol 1999;28:1167-71.

11 Zhang H, Kandel RP, Sharma B, et al. Risk factors for recurrence of postoperative trichiasis: implications for trachoma blindness prevention. Arch Ophthalmol 2004:122:511-16.

12 Bowman RJ, Faal $H$, Myatt $M$, et al. Longitudinal study of trachomatous trichiasis in the Gambia. Br J Ophthalmol 2002;86:339-43.

13 Burton MJ, Frick KD, Bailey RL, et al. Azithromycin for the treatment and control of trachoma. Expert Opin Pharmacother 2002;3:113-20.

14 Schachter J, West SK, Mabey D, et al. Azithromycin in control of trachoma. Lancet 1999;354:630-5.

15 Chern KC, Shrestha SK, Cevallos V, et al. Alterations in the conjunctival bacterial flora following a single dose of azithromycin in a trachoma endemic area. Br J Ophthalmol 1999;83:1332-5.

16 Dolin PJ, Faal H, Johnson GJ, et al. Trachoma in the Gambia. Br J Ophthalmol 1998;82:930-3.

17 Rosser DA, Laidlaw DA, Murdoch IE. The development of a "reduced $\log M A R^{\prime \prime}$ visual acuity chart for use in routine clinical practice. Br J Ophthalmol 2001;85:432-6.

18 Dawson CR, Jones BR, Tarizzo ML. Guide to trachoma control. Geneva: World Health Organization, 1981.

19 Smith PG, Morrow RH. Methods for field trials of interventions against tropical diseases: a "toolbox". Oxford: Oxford University Press, 1991

20 Burton MJ, Holland MJ, Faal N, et al. Which members of a community need antibiotics to control trachoma? Conjunctival Chlamydia trachomatis infection load in Gambian villages. Invest Ophthalmol Vis Sci 2003;44:4215-22.

21 Adamu Y, Alemayehu W. A randomized clinical trial of the success rates of bilamellar tarsal rotation and tarsotomy for upper eyelid trachomatous trichiasis. Ethiop Med J 2002:40:107-14.

22 Alemayehu W, Melese M, Bejiga A, et al. Surgery for trichiasis by ophthalmologists versus integrated eye care workers: a randomized trial. Ophthalmology 2004;111:578-84.

23 Burton MJ, Bailey RL, Jeffries D, et al. Cytokine and fibrogenic gene expression in the conjunctivas of subjects from a Gambian community where trachoma is endemic. Infect Immun 2004;72:7352-6.

24 Dawson CR, Marx R, Daghfous T, et al. In: Bowie WR, ed. Chlamydial infections. Cambridge: Cambridge University Press, 1990:271-8.

25 West SK, Munoz B, Mkocha H, et al. Progression of active trachoma to scarring in a cohort of Tanzanian children. Ophthalmic Epidemiol $2001 ; 8: 137-44$. 